can be learnt from a proper study of science, and, so far from any knowledge acquired by a boy before he is sixteen having but a slight intrinsic value, is it not a fact that all knowledge requiring mechanical dexterity, such as reading, writing, arithmetic, riding, swimming, talking foreign languages, playing a musical instrument, $\&$ c., can be far better acquired before the age of sixteen than later, and are not all these examples of knowledge possessing intrinsic value?

We are, however, quite at one with Sir Andrew in thinking that

" the age at which a boy should seriously begin any special studies, with a view to fit him technically for the profession he may have decided to follow, should not be earlier than seventeen or eighteen,"

But should not a sharp distinction be drawn between learning technology and acquiring the elementary principles of science? His warning that the zest for your life's work may be weakened by embarking on it too early certainly furnishes a potent, probably the most important, reason why lads who intend to become engineers should wait until they are eighteen, or at any rate seventeen, years old before they commence their professional education; for then, as is said in the address, they will be

"fresh and keen when others, who have been hammering away at semi-technical work from early boyhood, have become stale and are less vigorous."

For the same reason also, time devoted by a lad to learning off strings of scientific facts would be misspent, but not so, we think, would time given by even a child to the acquisition of scientific habits of thought. We do not defer teaching a lad the principles of morality until he is seventeen or eighteen for fear he should become tired of living a moral life, why then should the risk that a lad might weary of leading an intellectual one frighten us into excluding the principles of science from a good education?

In the address, "science, mechanical drawing, and such like" are classed together as things that may with advantage be omitted from the training of a lad before entering Elswick, provided he has had a good education. But can an education of the present day be termed "good" which lacks a training in those mental qualities which are classed under the head of scientific?

Great stress was laid by Sir Andrew Noble on the value of the knowledge which a person has gained for hiniself. He cited the results which "dauntless energy, untiring industry and patient search after truth" had achieved for Lord Armstrong, Watt, Stephenson and Faraday, but only as a proof "that a special technical education is not an absolute necessity." Do not the lives of these.men, however, teach us much more than this, viz. that the particular system of education, classical, mathematical, scientific, artistic or technicalin fact, any system of education ever invented-is less than nothing in enabling a man to rise to the top in comparison with the determination to succeed and the brains to do it?

The reason why certain branches of industry have almost abandoned this country, and why new branches that have been developed abroad have hardly taken root with us, is a topic deeply interesting to the manufacturer, but generally rather distasteful to the student, since he would prefer to be told that everything was done better, more cheaply and more expeditiously in his own country than in any other. Sir Andrew Noble, however, made even the part of his address which dealt with this subject appeal strongly to his audience, and for a remedy he thought that it was

"to theoretic and technical knowledge that we must chiefly

look. Consider, as an illustration, electricity in the service of No. 1563 . vul. 6o] man. Think of its innumerable applications, and of the number of hands dependent upon its industries. But for one man capable of designing or improving these powerful machines or delicate instruments, there are a thousand ready and able to carry out their designs. But it is the former who are the salt of the earth, and those who have the management of large concerns know well how to value them."

His patriotic statement (for it is true patriotism to help your own countrymen to learn the truth even if it be distasteful) that the success of our German competitors was not due "to their putting on the market inferior goods specially got up to imitate those of a superior class," but "to the far greater opportunities of technical study which are afforded in Germany," was as bold as we believe it to be true. For we were recently informed by an English manufacturer that certain things manufactured in England are now being stamped "Made in Germany," in order to obtain a readier sale for then in our own country.

But in addition to greater facilities being needed in Great Britain for the study of the applications of science to industry, greater belief in the value of such study is wanted, not only on the part of the English manufacturer, but also on the part of the English student. "You younger men," said Sir Andrew, "must do your part by seeking to avail yourselves to the uttermost of any such opportunities provided," and it might be added that the reason why that future "important commercial rival, Japan, is developing its manufacturing powers with an energy that is as remarkable as it is unexampled" is because even thirty years ago its young students absorbed with eagerness and rapt attention every scrap of scientific teaching which they could obtain. And they did so partly for their own personal benefit, but far more because each one felt that on his own exertions depended the fame and future of his mother country.

W. E. A.

\section{RESEARCH WORK AND THE OPENING OF} THE MEDICAL SCHOOLS.

$\mathrm{I}$ one sense at least, viz. his intellectual life, the medical student, natural enough in other respects, seems somewhat at variance with nature; his intellectual spring occurs simultaneously with nature's autumn. Brown October sees him change the abstractness of the class-room for the concreteness of the laboratory. Further, each successive autumn, after a period of summer hibernation, marks the advent of some change in his studies. The fully fledged doctor, too, whose daily round obliterates all distinction between term time and vacation, becomes infected in October with a revival of intellectuality, and whets his appetite by an attendance at the inaugural address delivered at his school, where he gets new knowledge or old dished-up afresh, and becomes generally imbued with the spirit of the time.

This year at least the medical student will not be able to lay any shortcomings which may occur during the ensuing academical year to the charge of insufficient or inadequate advice at its onset. At both the London and provincial schools the inaugural addresses, with regard to depth of meaning and also attractive eloquence, have left little to be desired.

In a short article such as the present it would be impossible to adequately reproduce, even in the most abridged form, the various "motifs" pervading the speeches delivered. One, however, constantly recurring, may be somewhat enlarged upon. Here and there and everywhere in the inaugural addresses we find the position of research to medicine and the medical profession cropping up. Occasionally this subject is mooted in the grossly material form, when, for instance, Sir James Crichton Brown frankly told his hearers at Manchester that although $70,000 l$. was an adequate sum so far, 
Manchester must be prepared to put its hand in its welllined pocket for an equal amount to keep pace with science, which is now so mobile and so expensive. Dr. Clifford Allbutt delivered an address at St. Thomas's, which mostly consisted of a strictly logical defence of theory and abstract learning. Those who read carefully Dr. Allbutt's address will find more in it even than this. The apostles of empiricism, to whom the almighty fact is alone of importance, are the worst enemies of what may collectively be termed medical research. Their bourgeois utilitarianism prevents them from appreciating or forwarding any branch of inquiry connected with the medical sciences which does not immediately result in something of use. Research to them is the quintessence of an abstractitude.

This mental attitude of a part of the profession, which fortunately is getting less and less, finds its expression in the position adopted by the influential public and lay committees. It is somewhat anomalous - at any rate, it appears so-that astute financiers, practical men accustomed to weigh the chances of ultimate dividends in the most complicated concerns, should so discount pathological and pharmacological research. It must be known to them that a large proportion of the drugs they take, and the curative remedies they employ, are made in Germany, and that thousands of pounds are spent annually on German products of this class which might perfectly well be produced at home. Those of them who wander so far from the Stock Exchange as St. Dunstan's Hill will find there a whole colony of German firms which supply these articles. A public which will wait for years for dividends so far as concerns South African securities, which will fill up readily the gaps in a Cape to Cairo railway scheme, although this at present can only be done by a somewhat lively imagination, is in clined to push and accelerate the scientific worker, and expect maximum results in minimum time. The success of the German manufacturer in products such as therapeutic sera and synthetic drugs is simply due to the fact that the German capitalist has waited for his dividends which he is now getting. Apart from the standpoint of mere commerce, it is somewhat galling to know that a crude product like coal-tar is at present exported from this country, and re-imported worked up in the shape of dye-stuffs and drugs.

To work one must have a workshop; a palace one does not need. This forms another great difficulty with regard to medical research in London. The authorities at the London hospitals rightly regard the patients as having the first charge upon the space and accommodation at their command. Space in London, especially so far as concerns the older foundations--such, for instance, as St. Bartholomew's and Guy's-is necessarily very valuable. This subject formed the keynote of some of the speeches at the old students' annual dinner at St. Bartholomew's. The Great Hall was full of old Bartholomew's men, who, under the chairmanship of Dr. Lauder Brunton and the secretaryship of Mr. Bruce Clarke, met to inaugurate the new academic year. Dr. Lauder Brunton, in a short but effective speech, proudly stated that the hospital, so far as its essentially medical aspect went, left nothing to be desired; quite so much, however, could not be said for the laboratory accommodation. Sir Norman Lockyer, whose opinion upon the subject of experimental technique oug ht certainly to be final, also deplored this want of laboratory space in so old and famous a medical school. Many difficulties special to medical research were discussed by Sir Norman, and research in this branch of knowledge was compared to research in the physical sciences. One of the difficulties was the question of time. The worker in the fields of the medical sciences must solve his problems often at once. He must be an opportunist. Stars and planets remained more or less the same, but this was not so with disease. Pressure from without, according to Hunter, causes hypertrophy or overgrowth, pressure from within atrophy or waste. If the pharmacological laboratory at St. Bartholomew's is not in a condition of healthy overgrowth, it is certainly not because pressure from without is wanting, for, according to Dr. Brunton, its confines have been narrowed down to some fourteen square feet. It was reassuring to be informed by the treasurer, Sir Trevor Lawrence, that arrangements were on foot which would ensure more ample accommodation to laboratory workers at Bartholomew's.

The London Hospital was fortunate in securing the presence of Dr. Haffkine, who made an excellent and humorous speech. The St. George's students were addressed by Dr. Howship Dickinson upon "Medicine Old and New." Dr. Mitchell Bruce, at Charing Cross, took the "Outlook of Medicine" as the subject of his address. This was, he said, at the present time hopeful, since the scientific method was being pursued in every department of medicine.

In laying stress upon the special difficulties of the time, one is perhaps rather apt to forget the causative origin of all the inaugural addresses, viz. the medical student himself. He comes in ample numbers, a sufficient testimony to the healthiness of the profession he aspires to join, from year to year, sometimes partially prepared by the universities, sometimes raw from school, to struggle with those life-long difficulties of the healing art, compared to which even examinations count as nothing. For five years, now, he must suffer many things of divers examiners, and finally emerge to meet the great problem of his life-the human individual, both healthy and diseased. Exact knowledge in the sense of physical exactitude will probably be denied to as yet many generations of medical students, even concerning the main problems of disease, and in spite of the progress that, thanks mostly to careful and continual laboratory work, often of an apparently abstract nature, has during the last century been made, our knowledge even now serves often merely to illuminate our ignorance, and however optimistic our hopes for the future we are forced to admit thatA thousand things are hidden still,
And not a hundred known.

F. W. T.

\section{DARK LIGHTNING FLASHES.}

I $S$ there such a phenomenon as dark lightning? This is a question that has often been raised, and as yet no satisfactory answer has been given. If dark flashes do really occur, then they should probably be both seen and photographed, and the former, one would think, would be the more simple way of recording them. A difficulty, however, here arises, for if we assume that both dark and bright flashes occur during a thunderstorm, then we must be careful not to mistake retina-fatigue dark flashes for actual dark flashes if they exist. Lord Kelvin (NATURE, vol. lx. p. 34I) has lately pointed out how, during a recent storm, he was able to confirm the existence of these apparent dark flashes; and in a more recent number of this journal (vol. lx. p. 39I) I published some observations corroborating the same view. It must be pointed out, however, that, although such observations indicate that the majority of dark flashes seen may be attributed to the cause of fatigue of the retina, it does not necessarily follow that dark flashes do not actually occur. Eye observations, therefore, do not help us as yet to give a satisfactory answer to this question.

Let us turn now to photography, and see what evidence we can gather from photographs of flashes taken during thunderstorms.

In dealing with this mode of recording flashes, we are NO. I 563 , VOL. 60 ] 